\title{
Detecting de novo insulin synthesis in embryonic stem cell-derived populations
}

\author{
Eadaoin Mc Kiernan ${ }^{1}$, Niall W. Barron*,1, Finbarr O'Sullivan, Paul Barham, \\ Martin Clynes, Lorraine O'Driscoll
}

National Institute for Cellular Biotechnology, Dublin City University, Dublin 9, Ireland

\section{A R T I C L E I N F O R M A T I O N \\ Article Chronology: \\ Received 12 October 2006 \\ Revised version received \\ 28 November 2006 \\ Accepted 19 December 2006 \\ Available online 30 December 2006}

Keywords:

Embryonic stem cells

Insulin

Differentiation

\begin{abstract}
A B S T R A C T
Several studies in recent years have described protocols, both genetic- and culture-based, that induce the differentiation of embryonic stem (ES) cells towards a pancreatic beta-cell type. The success of previous protocols in generating insulin-producing beta-cells has been questioned due in part to uncertainty regarding cell lineage but also due to the controversy regarding the source of any insulin detected in these cells. In an attempt to address the latter, we designed a novel assay that can identify de novo insulin synthesis. The method is based on metabolic labeling combined with a modified radioimmunoassay and will routinely detect less than $5 \mathrm{pg} / \mu \mathrm{l}$ of de novo insulin synthesis in lysates from the insulinoma cell line MIN6. This assay failed to detect any newly translated insulin in an ES cell-derived population generated using an adapted version of a previously published, 5-stage differentiation protocol. In combination with other techniques, including immunofluorescent staining and western blot analysis to detect and quantify C-peptide, we conclude that the majority of the insulin found in these differentiated ES cell cultures is medium-derived.
\end{abstract}

(c) 2006 Elsevier Inc. All rights reserved.

\section{Introduction}

ES cells are capable of unlimited self-renewal and multilineage differentiation. These unique characteristics make ES cells a potential source of insulin-producing cells for transplantation therapy [1-3]. Since 2000, several important and exciting reports have been published describing the derivation of insulin-positive cells from both mouse [4-9] and, to a lesser extent, human ES cell lines $[10,11]$. Several of these studies have been based on the derivation of insulinproducing cells using modified protocols that were originally designed to generate neurons, on the premise that the pancreas and central nervous system share developmental pathways [12-14]. A study published by Lumelsky et al. [4] described a 5-step protocol which selectively enriched for nestin-positive cells as pancreatic precursors [4]. Nestin is an intermediate filament protein found in neural precursors that has more recently emerged as a potential marker of intra-islet stem cells $[15,16]$. ES cell-derived 3-dimensional clusters, known as embryoid bodies (EB), generated using this 5-step protocol stained positive for insulin in addition to the other pancreatic endocrine hormones. The cells secreted insulin in response to glucose but did not correct hyperglycemia when injected into diabetic mice. Several further studies modified this protocol by: the addition of a $\mathrm{P} 13 \mathrm{~K}$ inhibitor [5], constitutive expression of Pax4 [6] and regu-

\footnotetext{
* Corresponding author. Fax: +35317005484.

E-mail address: niall.barron@dcu.ie (N.W. Barron).

${ }^{1}$ Contributed equally to this study.
} 
lated expression of $\mathrm{Pdx} 1$ [8], resulting in the generation of transplantable insulin-producing cells. Insulin-producing cells derived from ES cells improved glycemic control in diabetic mice short-term $[5,6]$.

Despite these encouraging reports, some doubts have been raised regarding the evidence for de novo insulin synthesis [17-19]. Several protocols depend on the addition of supplemental growth factors and nutrients to the media in a serumfree step-one of these added factors is insulin. The presence of this high concentration of exogenous insulin has led to the suggestion that apoptotic cells in the culture may be concentrating the hormone from the media [17]. In addition, insulin staining alone has been found to exaggerate genuine differentiation toward a beta-cell type and subsequent studies have focused on immunoreactivity for C-peptide as a means of 'beta-cell' determination (C-peptide being a by-product of insulin biosynthesis). More recently, authors have reported that ES-derived populations expressing insulin, and in some cases C-peptide, are devoid of granules typically found in beta-cells and are mostly apoptotic [18] and that insulin is released artifactually from differentiated ES cells [19]. The presence of neuronal-like phenotypes within the differentiated ES cultures [18] and the suggestion that insulin-positive cells may be extra-embryonic in origin [20] has also highlighted the need for stringent criteria to define true beta-cell identity. This may include: (a) measuring transcript expression of beta-cell associated genes as well as genes associated with other lineages, (b) measuring expression of key beta-cell marker proteins and (c) demonstrating functional de novo insulin synthesis.

In the present study we attempted to address some of the more controversial issues associated with the identification of 'beta-like' cells derived from mouse ES cells. We have devised a novel assay for detection of de novo insulin synthesis in order to identify functional, insulin-producing cells in vitro. The assay was subsequently applied to cells derived via a slightly modified version of the original Lumelsky protocol which reported insulin-producing cells containing $145 \mathrm{ng}$ of insulin per mg of protein. The murine insulinoma cell line, MIN6, was used to develop the assay. In addition, we investigated an alternative means for determining C-peptide expression which does not rely on immunostaining alone. We also measured expression of a range of multi-lineage markers to further characterize the complex mixture of cell types derived from the protocol used in this and other studies.

\section{Materials and methods}

\section{Cell culture and in vitro differentiation}

ES-D3 cells (ATCC, CRL-1934) were maintained on gelatincoated (Sigma) plastic in Dulbecco's modified Eagle's medium (DMEM) containing $25 \mathrm{mmol} / \mathrm{l}$ glucose, supplemented with 10\% FCS (ATCC, 30-2020), 1400 units/ml leukemia inhibitory factor (LIF) (Chemicon) and $0.1 \mathrm{mmol} / \mathrm{l} \beta$-mercaptoethanol at $37{ }^{\circ} \mathrm{C}$ and $5 \% \mathrm{CO}_{2}$. Differentiation was essentially as described previously [4] with slight modification i.e. cells were passaged 2-3 times on gelatin in the absence of feeder layers (stage 1) and all stage 3 (S3) cultures proceeded through to stage 4 (S4)
Stage 1: Routine culture of ES cells in DMEM (+LIF) on gelatin

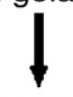

Stage 2: Generation of EBs in DMEM (-LIF) in suspension (4 days)

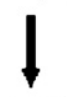

Stage 3: Selection of Nestin positive cells in ITSFn medium (7 days)

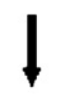

Stage 4: Expansion of cell clusters in $\mathrm{N2}$ medium containing B27 and bFGF (7 days)

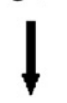

Stage 5: Induction of differentiation by withdrawal of bFGF from N2 medium and supplementing it with nicotinamide and $\mathrm{B} 27$ supplement (6 days)

Fig. 1 - Generation of Stage 5 (S5) 3-dimensional clusters from Stage 1 (S1) mouse ES-D3 cells. Insulin-containing supplements underlined. LIF, leukemia inhibitory factor; ITSFn, insulin transferrin selenium chloride fibronectin; bFGF, basic fibroblast growth factor; DMEM, Dulbecco's modified eagle medium.

without trypsinization/dissociation (Fig. 1). MIN6 cells were cultured as described previously [21].

\section{RT-PCR analysis}

Total RNA was isolated using Tri-Reagent (Sigma), according to the manufacturer's recommended protocol. cDNA was synthesized from $1 \mu \mathrm{g}$ total RNA using MMLV-RT (Sigma) and oligo-dT in a $20 \mu \mathrm{l}$ volume. Gene specific primer pairs $\left(5^{\prime}-3^{\prime}\right)$, amplicon size and annealing temperature were as shown in Supplementary Table 1 . PCR conditions were as follows: initial denaturation at $95^{\circ} \mathrm{C}$ for $3 \mathrm{~min}, 25-30$ cycles at $95^{\circ} \mathrm{C}$ for $30 \mathrm{~s}$, $30 \mathrm{~s}$ at annealing temperature, $30 \mathrm{~s}$ at $72{ }^{\circ} \mathrm{C}$ and a final $7 \mathrm{~min}$ at $72{ }^{\circ} \mathrm{C}$. An internal endogenous control, GAPDH (expression levels of which were found to be similar in all samples), was included for normalization. The PCR products were size fractionated in $2 \%$ agarose.

\section{Real time PCR analysis (qPCR)}

Beta-cell specific targets were analyzed by qPCR in order to accurately quantify their expression level. For this purpose, cDNA was prepared from $1 \mu \mathrm{g}$ total RNA using Moloney murine leukemia virus (MMLV) reverse transcriptase (Sigma) and oligo-dT in a $20 \mu \mathrm{l}$ volume. The cDNA was amplified, by qPCR, using an ABI 7500 Real Time PCR System (Applied Biosystems, Foster City, CA). Probes and primer pairs were designed for insulin I, insulin II, glut2 and $\beta$-actin (Supplementary Table 1) using Primer Express 2.0 Software for quantitative detection of amplified products. The temperature profile of the reaction was $50{ }^{\circ} \mathrm{C}$ for $2 \mathrm{~min}, 95{ }^{\circ} \mathrm{C}$ for 
$10 \mathrm{~min}, 40$ cycles of $95^{\circ} \mathrm{C}$ for $15 \mathrm{~s}$ and $60^{\circ} \mathrm{C}$ for $1 \mathrm{~min}$. Expression levels were normalized using the GAPDH signal (internal control) compared to undifferentiated ES-D3 cells (reference). Individual samples were run in triplicate.

\section{Immunofluorescence (IF)}

Stage 1 (S1) ES-D3 cells, Stage 5 (S5) dissociated clusters (cells pre-incubated in $2 \mathrm{mmol} / \mathrm{l}$ EDTA for $10 \mathrm{~min}$ and then dissociated in $0.25 \%$ trypsin plus $0.05 \%$ EDTA for $10 \mathrm{~min}$ ) and MIN6 cells were allowed to adhere to poly-L-ornithine coated chamber slides (Biosciences) for $6 \mathrm{~h}$ prior to being fixed in $4 \%$ paraformaldehyde for $45 \mathrm{~min}$ at $4{ }^{\circ} \mathrm{C}$. Cells were treated with $1 \%$ Glycine in PHEM buffer (60 mmol/l PIPES, $25 \mathrm{mmol} / \mathrm{l}$ HEPES, $10 \mathrm{mmol} / \mathrm{l} \mathrm{EGTA}, 2 \mathrm{mmol} / \mathrm{l} \mathrm{MgCl}, \mathrm{pH}$ 6.9) for $30 \mathrm{~min}$ to reduce auto-fluorescence and permeabilized with $0.2 \%$ Triton $\mathrm{X}-100$ in PHEM buffer for 2-4 h at room temperature. Cells were blocked with $20 \%$ goat's serum overnight at $4{ }^{\circ} \mathrm{C}$. Following blocking, cells were immunostained for insulin (monoclonal anti-insulin antibody, R\&D Systems, $5 \mu \mathrm{g} / \mathrm{ml}$ ) and C-peptide 2 (polyclonal rabbit anti-mouse C-peptide antibody, gift from Hagedorn Research Institute, 1:2000) overnight at $4^{\circ} \mathrm{C}$. Cells were rinsed with PHEM buffer and incubated with appropriate secondary antibody for $2 \mathrm{~h}$ at room temperature. Cells were counterstained with DAPI (Vectashield with DAPI, Vector Laboratories). Slides were imaged on a Leica confocal microscope.

\section{Western blot analysis}

Lysed cell sample containing $15 \mu \mathrm{g}$ protein (lysed in $1 \times$ protease inhibitor cocktail in $\mathrm{H}_{2} \mathrm{O}$ (Roche Applied Science (11697498001) in a tablet form) and sonicated) was mixed with an equal volume of $2 \times$ Laemmli sample buffer (Sigma) and boiled for $3 \mathrm{~min}$. Proteins were separated on a 12\% Bis-Tris gel (NUPAGEl). The electrophoresis conditions were $200 \mathrm{~V}$ and $90 \mathrm{~mA}$. The gels were run for $40 \mathrm{~min}$. The proteins were transferred from the gel to a PVDF membrane (Boehringer Mannheim) in 1x Premixed Tris/Glycine Buffer (Biorad) at a current of $34 \mathrm{~mA}$ and $15 \mathrm{~V}$ for $20 \mathrm{~min}$. The membrane was blocked with $5 \%$ non-fat dried milk (Cadburys: Marvel skimmed milk) in $1 \times$ TBS (Sigma). After blocking, the membrane was rinsed with TBS-Tween ${ }^{\mathrm{TM}}$ and then incubated with polyclonal rabbit anti-mouse C-peptide antibody (1:5000) overnight at $4{ }^{\circ} \mathrm{C}$. This was subsequently incubated with secondary 1:5000 anti-rabbit IgG (Sigma A4914). Detection was carried out with ECL chemiluminescence substrate (Amersham RPN 2109). Following chemiluminescent detection, blots were again washed and blocked as described and re-probed for an internal standard i.e. GAPDH.

\section{Insulin content and GSIS analysis}

GSIS analysis was performed as previously described [21]. Cells were lysed in $0.1 \mathrm{M} \mathrm{NaOH}$ at $4{ }^{\circ} \mathrm{C}$. (Pro) insulin content was assessed by ELISA (Mercodia).

\section{Metabolic labeling of intracellular insulin}

MIN6 and S1 ES-D3 cells were seeded at $1 \times 10^{6}$ cells per well in a 6 well culture plate and incubated overnight in culture media
(LIF included in ES-D3 medium). S5 differentiated ES-D3 cells were generated as described above. De novo synthesized proteins were labeled by inclusion of ${ }^{35} \mathrm{~S}$-L-cysteine in the culture medium (metabolic labeling). Briefly, growth medium was removed from cell cultures and cells were washed with PBS. One milliliter of Cys-medium (DMEM lacking cysteine and $10 \%$ dialysed fetal calf serum (Sigma)) was added to each well and incubated at $37{ }^{\circ} \mathrm{C}$ for $20 \mathrm{~min}$ to deplete intracellular cysteine levels. This was removed and replaced with $1 \mathrm{ml}$ of the same medium supplemented with $100-250 \mu \mathrm{Ci} / \mathrm{ml}{ }^{35} \mathrm{~S}-\mathrm{L}-$ cysteine (specific activity $>1000 \mathrm{Ci} / \mathrm{mmol}$ ). Control 'cold' cultures received complete, normal growth media. The cultures were then incubated at $37^{\circ} \mathrm{C}$ for $6 \mathrm{~h}$ in $5 \% \mathrm{CO}_{2}$. Cells were lysed, after removing the labeling media and washing twice with cold PBS, by addition of $400 \mu \mathrm{l} 0.1 \mathrm{M} \mathrm{NaOH}$. These extracts were stored at $-80{ }^{\circ} \mathrm{C}$ before analysis.

\section{Competitive RIA for detection of de novo insulin synthesis}

Lysates were thawed and spun for $5 \mathrm{~min}$ at $12,000 \mathrm{rpm}$ at $4{ }^{\circ} \mathrm{C}$. An aliquot of the supernatants was kept aside for total protein determination and quantification of total insulin content. The remainder was passed through a $50 \mathrm{kDa}$ cutoff spin filtration unit (Centricon) to remove high molecular weight proteins. For Competitive RIA analysis of the samples, a rat insulin ELISA kit (Mercodia) was used with the following modifications:

Blocking: $50 \mu \mathrm{l}$ of Conjugate Buffer was added to each well and $25 \mu \mathrm{l}$ of a 1 in 10 dilutions of 'cold' matched sample lysate (i.e. MIN6 wells blocked with 'cold' MIN6 lysate) followed by a 1-h incubation at room temperature and $100 \mathrm{rpm}$.

Competitor: the blocking solution was removed and the wells washed $(\times 6)$ with $1 \times$ Washing Solution (supplied in kit). Fifty microliters of Binding Buffer was added to each well followed by $25 \mu$ l of a dilution series of pure insulin (Sigma) ranging from $250 \mathrm{ng} / \mu \mathrm{l}$ down to $2.5 \times 10^{-5} \mathrm{ng} / \mu \mathrm{l}$. The plate was again incubated at room temperature for $1 \mathrm{~h}$ at 100 rpm to allow equilibration.

Sample Binding: $25 \mu \mathrm{l}$ of a 1 in 5 dilution of the radio-labeled, ultra-filtered lysate was added to each well and incubated at room temperature for $2 \mathrm{~h}$ at $100 \mathrm{rpm}$.

Measurement: Unbound protein was removed by discarding the binding solution and washing the wells $(\times 6)$ with Washing Buffer. Bound protein was eluted from the plate by proteolytic cleavage of the capture antibody with $100 \mu \mathrm{l} /$ well of papain digestion buffer at $37^{\circ} \mathrm{C}$ overnight $(200 \mathrm{mM}$ sodium phosphate, pH 7, 2 mM EDTA, $10 \mathrm{mM}$ L-cysteine and $0.2 \mathrm{mg} / \mathrm{ml}$ papain (Sigma)). The amount of radiolabeled material released from each well was measured in a Beckman-Coulter scintillation counter (100 $\mu$ l digestion buffer in $5 \mathrm{ml}$ Ecolite scintillation fluid, $1 \mathrm{~min}$ reading time on ${ }^{35}$ S channel).

\section{Results}

A 5-stage protocol was used to differentiate ES-D3 cells into insulin-expressing cell types (Fig. 1). Stages 3-5 medium 
contains exogenous insulin. These cells were subsequently tested for de novo insulin synthesis. Morphological changes occurring over the 5 stages were broadly in keeping with what was reported elsewhere [4,18] (Figs. 3A-E).

\section{Multi-lineage marker expression in Stage 5 differentiated} cultures

S1 and S5 cultures were analyzed by semi-quantitative RTPCR and qPCR. A number of early developmental markers, i.e. Pdx1, GATA4 and nestin, were detected at low levels in S1 ESD3 cells. Germ line specific transcription factor Oct 4 was slightly, but consistently, down-regulated between S1 and S5. Multi-lineage marker expression was detected in the S5 culture (Fig. 2A). Induced expression of pancreatic transcription factors $\mathrm{Pdx} 1$ and $\mathrm{Pax} 4$ occurred during the differentiation protocol. In the case of $\mathrm{Pdx} 1$ there is a faint band in the $\mathrm{S} 1$ cells and one could argue that these cells express an extremely low amount of Pdx1 mRNA. If so this may be a direct result of culturing the cells on gelatin without feeder layers. It has been previously shown by Lumelsky et al. that culturing ES cells on gelatin triggers Pdx1 mRNA expression. The S5 culture expressed pancreatic beta-cell markers; type 2 glucose transporter (glut2), insulin I, insulin II (Fig. 2B) and islet alpha cell marker, somatostatin (Fig. 2A). Pancreatic polypeptide (PP) and glucagon mRNA were not detected at any stage. Increased expression of the oligodendrocyte marker myelin basic protein (MBP) and induced expression of the astrocyte marker glial fibrillary acidic protein (GFAP) were observed between S1 and S5. Differentiated S5 cells also expressed extra-embryonic markers GATA4, Oct 4 and alpha fetoprotein (AFP). Apoptotic marker expression, i.e. bcl-2 associated $\mathrm{X}$ protein (bax) and caspase 3 remained unchanged between S1 and S5 (Fig. 2A).

\section{Insulin/C-peptide protein expression}

Immunofluorescent staining was used to identify insulin and C-peptide positive cells in the differentiated S5 culture. S1 ESD3 cells and the murine insulinoma cell line MIN6 represent negative and positive biological controls, respectively. S1 ESD3 cells were negative for insulin (Fig. 3F) but, unexpectedly, positive for C-peptide (Fig. 4A). Apparent C-peptide staining localized to the nucleus. MIN6 cells stained positive for both insulin (Fig. 3I) and C-peptide (Fig. 4C) as expected. A distinct punctate staining pattern was observed in MIN6 cells for both proteins. A sub-population of S5 differentiated clusters displayed a similar insulin-staining pattern to that of the MIN6 'beta-cell' phenotype (Figs. 3G, H). Immunoreactivity for $\mathrm{C}$-peptide was detected in a significant proportion of the S5 differentiated culture (Fig. 4B). In most cases, the anti-Cpeptide antibody stained in a cytoskeletal-like pattern. Immunoreactivity for C-peptide was also observed in another cell line that should be negative- the mouse mammary cell line 4TI (Fig. 4D). Specificity of the C-peptide antibody was checked by western blot (Fig. 4E). MIN6 cells were used as a positive control. S1 ES-D3, 4TI and FVB\#C (fibroblast cell line derived from mouse ear) were used as negative control cell lines. The C-peptide antibody recognized a specific band for the C-peptide protein at the expected size, $3 \mathrm{kDa}$ in the MIN6
A

$\begin{array}{ll}\text { Pluripotent } & \mathrm{T} \text { Oct4 } \\ & \mathrm{T} \text { PP } \\ \text { Endocrine } & \text { somatostatin } \\ & \perp \text { glucagon }\end{array}$

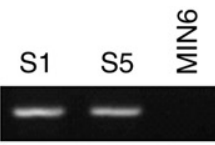

Transcription

Factors

$\left\lceil\begin{array}{l}\text { Pax4 } \\ P d x 1\end{array}\right.$

Extra-Embryonic $\perp_{\text {AFP }}^{\text {Gata4 }}$

Exocrine Pancreas I Amylase

Neuronal $\quad\left[\begin{array}{l}\text { Nestin } \\ \beta \text { III Tub } \\ \text { GFAP } \\ \text { MBP }\end{array}\right.$

$\begin{array}{ll}\text { Apoptopic } & I_{\text {Bax }}^{\text {Caspase3 }} \\ \text { Control } & I_{\text {Gapdh }}\end{array}$
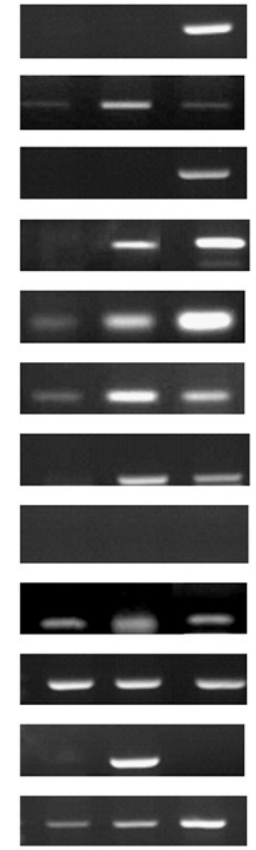

$--$

$--$

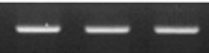

B

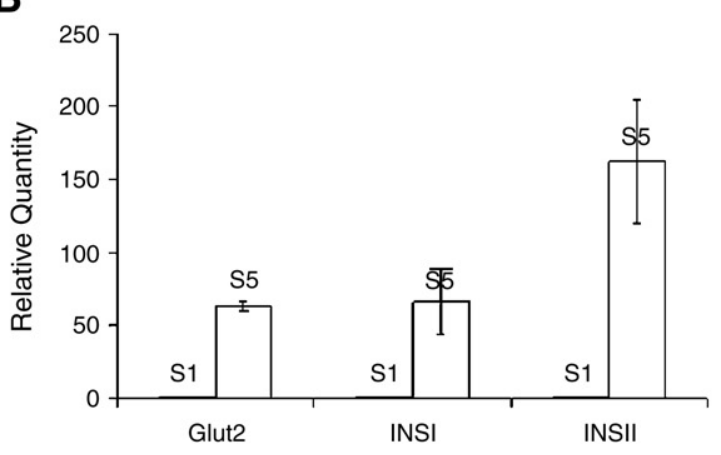

Fig. 2 - (A) Semi-quantitative RT-PCR analysis of multi-lineage marker expression in S1 (Stage 1) and S5 (Stage 5 ) cultures. Results were reproduced in four independent experiments. $\boldsymbol{\beta}$ III Tub, $\boldsymbol{\beta}$ III tubulin; GFAP, glial fibrillary acidic protein; MBP, myelin basic protein; AFP, alpha-fetoprotein; PP, pancreatic polypeptide. (B) qPCR analysis of glut2, insulin I and insulin II mRNA expression in S1 (Stage 1) and S5 (Stage 5) cultures. Relative quantity of mRNA expression in stage 1 cells set to 1 . Results represent means \pm SD from three independent experiments. INS, insulin.

cell line. C-peptide protein expression was not detected in the S5 differentiated culture (Fig. 4E, S5A and S5B). We noted multiple non-specific higher molecular weight bands in both positive and negative control cell lines (data not shown). 


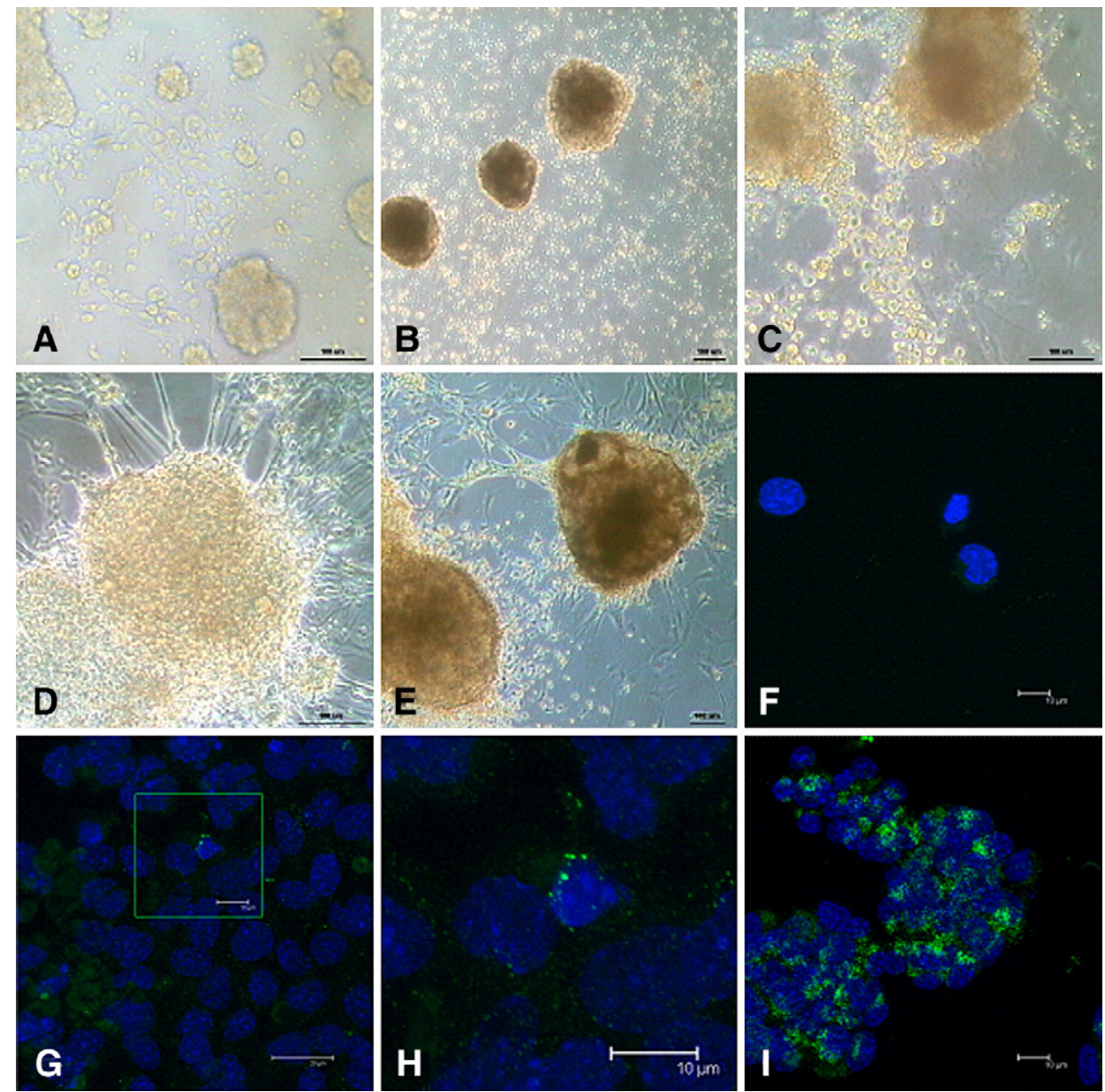

Fig. 3 - (A-E) Phase contrast images. (A) S1. ES-D3 cells cultured on gelatin. (B) S2. Embryoid bodies in suspension. (C) S3. Cells cultured in ITSFn medium. (D and E) S4 and S5. Neuronal-like cells protrude from 3-dimensional clusters. (F-I) Immunostaining for insulin. (F) S1. ES-D3 cells are negative for insulin. (G) S5. Insulin is expressed in a sub-population of cells. (H) S5. Punctate insulin staining is visible in a subset of cells. (I) MIN6. Insulin is expressed in a high proportion of cells (insulin, green; DAPI nuclear stain, blue). Scale bar $=100 \mu \mathrm{m}(\mathrm{A}-\mathrm{E}), 10 \mu \mathrm{m}(\mathrm{F}, \mathrm{H}, \mathrm{I})$ and $20 \mu \mathrm{m}$ (G).

Intracellular insulin content and in vitro glucose-stimulated insulin secretion

S1 ES-D3 cells did not contain insulin when assayed by ELISA. The S5 differentiated culture contained approximately $36 \mathrm{ng}$ insulin per mg protein (Fig. 5A). These ES-derived cells also constitutively secreted insulin although they did not exhibit a significantly increased secretory activity in response to glucose (Fig. 5B). MIN6 cells demonstrated functional GSIS by increasing insulin release approximately 4-fold over the glucose range tested (3.3-26.7 $\mathrm{mmol} / \mathrm{l})$.

\section{De novo insulin synthesis}

The novel assay we designed to identify de novo insulin synthesis consisted of metabolic labeling (ML) of total cellular protein over a $6 \mathrm{~h}$ time period followed by a modified radio-immunoassay (MRIA). We used the MIN6 cell line as a positive control to develop and prove the utility of the assay. The $6 \mathrm{~h}$ labeling timeframe ensured that a significant percentage of newly synthesized insulin incorporated
${ }^{35} \mathrm{~S}$-L-cysteine. Increasing this incubation to $24 \mathrm{~h}$ had only a minor benefit in terms of increased sensitivity whereas decreasing to $1 \mathrm{~h}$ reduced sensitivity 10-fold (data not shown). Total protein was extracted and the lysates were fractionated by ultra-filtration to remove larger proteins $(>50 \mathrm{kDa})$. We found that including this step dramatically decreased the level of background signal in the subsequent MRIA step as well as decreasing the noise in sampling (high standard deviation). We found that removing a large population of radio-labeled, 'sticky' proteins greatly improved assay performance (data not shown). It should be noted that this step also removes a small proportion (5-10\%) of the total insulin in the sample (measured by ELISA) - probably due to retention of larger aggregates by the membrane (data not shown). For simplicity, all measurements are related in terms of total protein prior to filtration. This is to avoid overrepresentation of the insulin content (per mg of protein) due to the removal of a large proportion of high molecular weight proteins during ultra-filtration.

In the subsequent MRIA, radio-labeled insulin in the lysate was bound by the antibody coated on the ELISA plate, eluted 

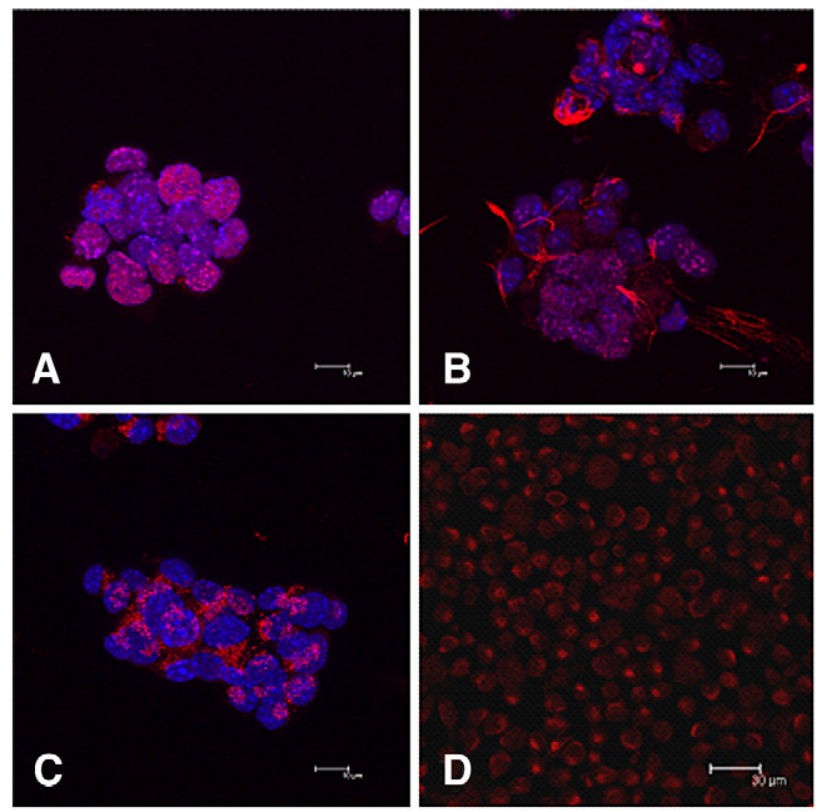

E

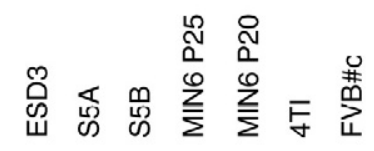

C-peptide: $3 \mathrm{kDa}$

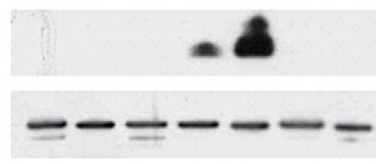

GAPDH: $37 \mathrm{kDa}$

Fig. 4 - (A-E) Analysis for C-peptide expression. (A-D) Confocal images. (A) Stage 1 (S1). ES-D3 cells stain positive for C-peptide expression. Staining is localized to the nucleus. (B) Stage 5 (S5). Cytoskeletal-like structures stain positive for C-peptide expression. (C) Positive control cell line MIN6. Staining for C-peptide is localized to the cytoplasm. (D) Negative control cell line 4TI. Cells stain positive for C-peptide expression (C-peptide, red; DAPI nuclear stain, blue; C-peptide overlapping DAPI, pink). Scale bar $=10 \mu \mathrm{m}$ (A, B, C) and $20 \mu \mathrm{m}$ (D). (E) Western blot analysis. The C-peptide antibody recognizes a specific band for $\mathrm{C}$-peptide protein ( $3 \mathrm{kDa}$ ) in the MIN6 positive control cell line.

by digestion of the antibody with papain and the radioactive signal measured by scintillation counting. By including known, increasing concentrations of competitor substrate (unlabeled insulin) during binding, we were able to detect a drop in radio-labeled insulin bound to the antibody. At low concentration (up to $2.5 \times 10^{-4} \mathrm{mg} / \mathrm{ml}$ ) there was no change in the amount of labeled insulin bound to the antibody but as this increased (maximum $0.25 \mathrm{mg} / \mathrm{ml}$ ) there was a sudden drop in counts from the plate (Fig. 6A). This is a result of the plate binding capacity being saturated with competitor prior to sample lysate addition. By plotting various dilutions of MIN6 protein lysate (expressed in terms of total insulin measured by conventional ELISA) against the counts per minute (cpm) detected, we were able to generate a standard curve that could be used to determine the minimum detectable level of labeled insulin in a sample (Fig. 6B).
Applying the equation of the slope of the line we determined that the lowest theoretical concentration of de novo synthesized insulin detectable in this assay is $0.38 \mathrm{ng} / \mathrm{ml}$. However, this would be very close to background levels therefore using a cut-off of $3 \times \mathrm{SD}$ above this as a minimum would be more practical ( $\mathrm{SD}= \pm 12 \mathrm{cpm}$ for highest dilution). This gives a minimum detectable quantity of $0.71 \mathrm{ng} / \mathrm{ml}$.

Having successfully identified de novo insulin synthesis in the control MIN6 cells, we applied the assay to S5 differentiated ES-D3 cells, with S1 untreated ES-D3s as a negative control. First we measured the amount of total insulin in the lysates by conventional ELISA, including MIN6 as a positive control. The control is included to account for inter-assay variations in specific activity of radioisotope, labeling efficiency, cell lysis, etc. We also measured total protein content prior to ultra-filtration. As can be seen in Table 1, there was a small but significant quantity of insulin detected by ELISA in the S5 cells, similar to levels found previously. When analyzed using the competitive MRIA, the lysate from undifferentiated
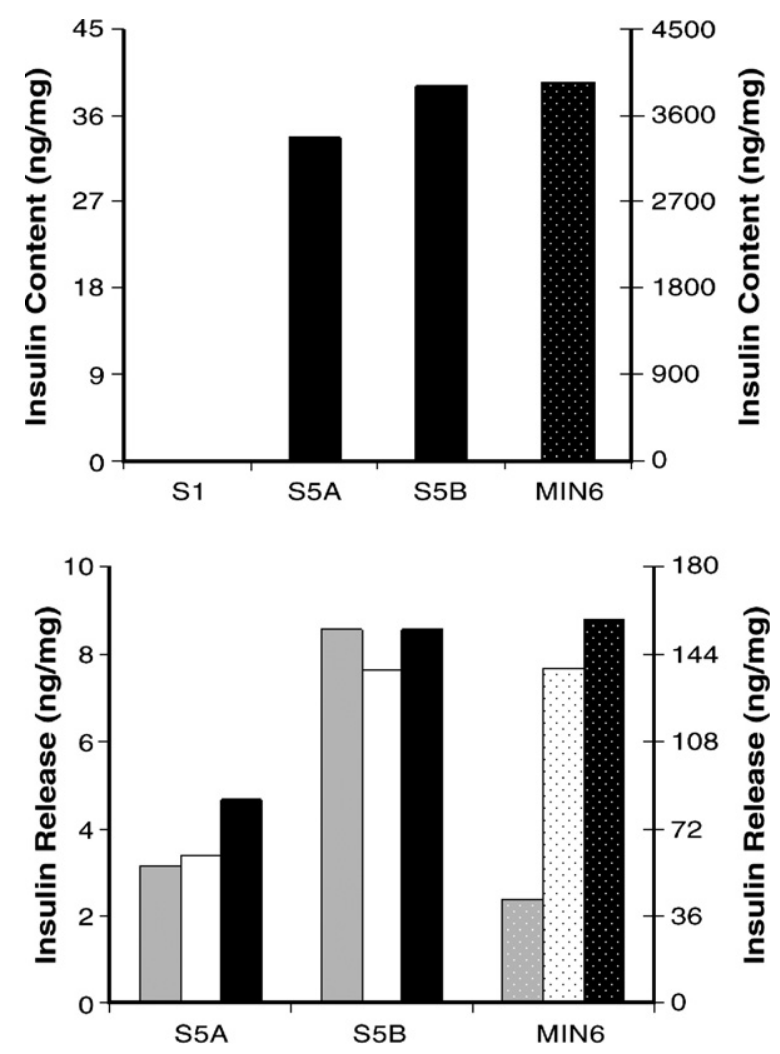

Fig. 5 - (A) Intracellular insulin content. Insulin content was normalized to the amount of protein in each sample.

Stage 1 ES-D3 (S1) and MIN6 represent negative and positive biological controls respectively. (B) Insulin secretion was measured by ELISA and normalized to total cellular protein. Stage 5 differentiated clusters were pre-incubated for $1 \mathrm{~h}$ with Krebs buffer containing $3.3 \mathrm{mM}$ glucose. Cells were subsequently incubated with Krebs buffer containing $3.3 \mathrm{mM}$ (gray), $16.7 \mathrm{mM}$ (white) and $26.4 \mathrm{mM}$ (black) glucose. Data are representative of two independent experiments, Stage $5 \mathrm{~A}$ (S5A) and Stage 5B (S5B) (MIN6 data plotted on secondary axis). 

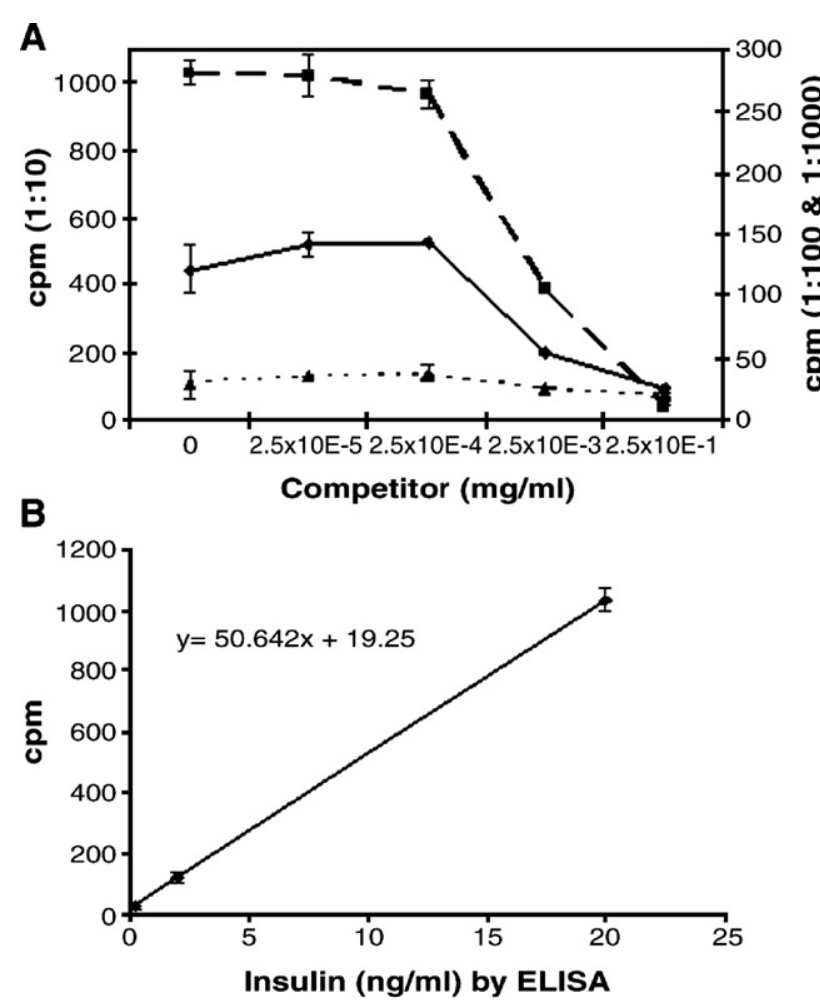

Fig. 6 - (A) Competitive binding of radio-labeled and non-labeled insulin to ELISA plate. Increasing the amount of 'cold' competitor insulin from 0 to $0.25 \mathrm{mg} / \mathrm{ml}$ in the well displaces bound MIN6-derived labeled insulin. Metabolic labeled MIN6 lysate diluted 1:10 (- - -), 1:100 (-) and 1:1000 (........). (B) Radioactive counts (cpm) versus total insulin concentration. A standard curve was generated by plotting total, bound cpm in non-competed, serial (10-fold) dilutions of MIN6 lysate against total insulin concentration as determined by ELISA. For very precise quantitation in any cell extract, a standard curve must be prepared as part of each experiment, due to inter-assay variations in labeling efficiency and specific activity.

ES cells showed a low level of radioactive counts $(\sim 400 \mathrm{cpm})$ and there was no detectable decrease at high concentrations of competitor, as expected (Fig. 7). The background signal was similar for the S5 cells but, significantly, high concentration

\section{Table 1 - Detection of de novo insulin in cell lysates}

Protein Total Insulin Insulin $\mathrm{cpm}^{\mathrm{a}} \mathrm{cpm}^{\mathrm{b}}$ $(\mathrm{mg} / \mathrm{ml}) \quad(\mathrm{ng} / \mathrm{ml}) \quad \mathrm{ng} / \mathrm{mg}$ Protein

\begin{tabular}{llccrl}
\hline ES-D3 & 0.323 & 1.96 & 6.07 & 452 & $438 \pm 13$ \\
Stage 5 (S5) & 2.35 & 88 & 37.4 & 380 & $368 \pm 16$ \\
MIN6 & 0.341 & 2986 & 8757 & 2861 & $155 \pm 4$ \\
\hline
\end{tabular}

Protein concentration refers to total prior to ultra-filtration. Total insulin concentration was determined by mouse (ultra-sensitive) ELISA. Counts per minute $(\mathrm{cpm})$ are those detected in diluted samples (1:5).

a cpm detected without addition of competitor.

b $\mathrm{cpm}$ detected after addition of high concentrations of competitor.

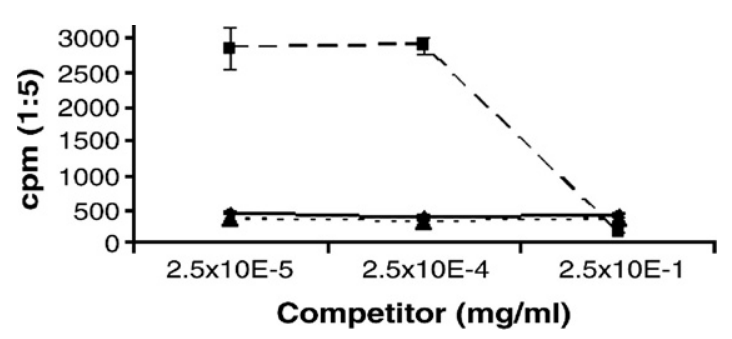

Fig. 7 - Competitive MRIA. MIN6 (- - -), S1 ES-D3 (-) and S5 (.......). All samples lysed in $\mathrm{NaOH}$ and diluted 1:5. Increasing the amount of 'cold' competitor insulin from 0 to $0.25 \mathrm{mg} / \mathrm{ml}$ displaces bound MIN6-derived labeled insulin; however, there is no displacement of labeled insulin observed in the S1 ES-D3 and S5 samples.

competitor did not cause any drop in the signal demonstrating absence of detectable, bound, radio-labeled insulin. This would suggest that the cells do not synthesize the majority of the $88 \mathrm{ng} / \mathrm{ml}$ insulin detected by ordinary ELISA.

\section{Discussion}

ES-derived cell types generated in recent protocols [4-9] have remained largely uncharacterized, apart from the identification of a small proportion of insulin/C-peptide positive cells within isolated sub-populations. Some of these protocols have reported the derivation of neuronal phenotypes [4,5,8,17-19] within differentiated populations whereas a more recent publication has suggested that ES-derived insulin-positive cells are actually extra-embryonic in origin [20]. In light of these findings, we undertook to investigate the nature of the cells as well as develop another means of establishing the presence of de novo synthesized insulin. We found that ES-derived, S5 clusters expressed markers representative of neuronal/glial lineage (GFAP, MBP, $\beta$ III tubulin), extra-embryonic lineage (GATA4, AFP, Pdx1) and pancreatic endocrine lineage ( $\operatorname{Pax} 4$, insulin I, insulin II, glut2) indicating the presence of multiple cell types in S5 clusters (Fig. 2). The derivation of such a complex culture may be a result of the nestin selection at $\mathrm{S} 3$ of the protocol (serumfree, ITSFn-supplemented medium). Nestin has been accepted as a marker of neuronal progenitor cells; however, the cumulative data from recent studies suggest that nestin expression in ES-derived progeny represents a property of multi-lineage progenitors that have the potential to develop into neuroectodermal, endodermal and mesodermal lineages [22]. The study reported by Lumelsky et al. indicated the derivation of cells expressing all pancreatic hormones [4]; however, both the study described here and others [18] failed to detect PP or glucagon mRNA expression in ES-derived cultures (Fig. 2A). This may be due to slight variations in the protocols such as lack of feeder cells, handling (trypsinization at certain stages) and cell type.

ES-derived cells did not show any sign of apoptosis. RTPCR analysis demonstrated that there was no change in bax or caspase 3 mRNA expression between S1 and S5 (Fig. 2A). S5 cell nuclei were round and robust rather than small and fragmented (as would be expected during apoptosis) 
(Figs. 3G, H). This finding contradicted that of recent publications [18,19], where a high incidence of apoptosis was reported in ES-derived cells. The discrepancy may be due to a modification in protocol at the end of S3. Following our protocol, all cells present at the end of S3 were maintained in culture without disruption and carried through S4. In other studies $[4,18,19]$, cell cultures were dissociated at this point and allowed to reattach before entering $\mathrm{S} 4$, perhaps putting the cells under stress and inducing apoptosis.

The identification of a beta-cell phenotype within differentiated populations has proven to be a challenge to all research groups. Commonly used supplements such as B27 and N2 include a high insulin content contributing to an overall insulin concentration in the culture medium exceeding that of circulating levels by 1000-fold [17] (Fig. 1). It is therefore difficult to ascertain whether insulin-positive cells are a direct result of insulin uptake or genuine de novo synthesis and secretion. Immunoreactivity to C-peptide [17] as well as assaying C-peptide release [19], in conjunction with that of insulin, has subsequently been employed as a more definitive means of demonstrating authentic beta-cell function. However, in the present study we found that the polyclonal Cpeptide antibody detected C-peptide expression in all ESderived cells whereas insulin protein expression was only detected in an isolated population of cells (Figs. 3G, H and 4B). Using the same antibody, Kahan et al. had found that the antiC-peptide antibody detected significantly more positive cells in a region than either of two monoclonal antibodies to insulin [23].

In the present study we drew our conclusions from IF data on the pattern and localization of staining, as well as inclusion of positive and negative biological controls. We found that C-peptide staining was not indicative of granular insulin staining as observed in the positive control phenotype MIN6 (Figs. 4B, C). Staining was localized to the nucleus and not to the cytoplasm as one would expect (Fig. 4B). The anti-C-peptide antibody also resulted in significant staining in 'negative' control cell lines i.e. S1 ES-D3 and mouse mammary 4TI cells (Figs. 4A, D). Western blot analysis confirmed that the antibody recognized a specific band for C-peptide at the expected size ( $3 \mathrm{kDa}$ ) (Fig. 4E). This antibody is useful for western blot analysis where one can distinguish between specific and non-specific bands based on molecular weight; however more caution is required for IF analysis. This is supported by the complete absence of specific bands in western blots of lysates from all cells tested (including S5 cells) except the MIN6 control—this despite broadly similar staining abundance and intensity in IF analyses. It is our belief that apparent C-peptide positivity in many IF/ICC (immunocytochemistry) studies may be overrepresented significantly in relation to actual levels in ES-derived cell populations.

By ELISA we detected approximately $36 \mathrm{ng}$ insulin per $\mathrm{mg}$ of protein in the $\mathrm{S} 5$ culture (Fig. 5A). Insulin was released from these cells but not in a glucose dependent manner (Fig. 5B). There are many potential reasons why the ES-derived cells did not respond to glucose stimulation. Firstly, the very low abundance of insulin-positive cells in the final mixed population may simply have made it impossible to detect any GSIS. In addition, though there are insulin-positive cells present, they may not be fully differentiated and may not have all the molecular machinery characteristic of a beta-cell. For example they may not be capable of glucose uptake in a manner that stimulates secretion of insulin. Finally, though insulin is present in the cells, it may be stored inappropriately. In a further effort to definitively identify de novo insulin biosynthesis in cultured cells, we developed a novel assay based on metabolic labeling (ML) followed by a modified radio-immunoassay (MRIA). In summary, the ML step radioactively labels all newly translated, cysteine-containing proteins (6 residues in insulin) by inclusion of ${ }^{35} \mathrm{~S}$-L-cysteine in the culture medium. The subsequent MRIA specifically binds insulin present in the cell lysate - both labeled and unlabeled - the former of which is detected by scintillation counting. We chose an ELISA-based method for a couple of reasons. Firstly, the plates are available commercially and should perform reasonably consistently. Furthermore, this format is more compatible with higher sample throughput, including replicates, compared to say, a bead-based affinity column. Finally, total cellular insulin is most conveniently measured by ELISA so maintaining the same platform for this assay made sense.

To develop and test the MRIA we used the mouse insulinoma cell line MIN6, which actively synthesizes and secretes insulin. We were particularly interested in determining the sensitivity limits of the assay given its intended use on ES cell-derived cultures that would be expected to synthesize very small quantities, if any, of the hormone. We first established that $6 \mathrm{~h}$ was sufficient time for the ML stepincreasing this time only marginally improved the performance of the assay overall. It should be noted that this is based on results generated using MIN6 cells and that insulin synthesis and turnover (secretion) rates are likely to be different depending on cell type. A second issue that we addressed concerned the specificity of the MRIA. Although the assay uses a commercial insulin ELISA plate for insulin capture (immunosorption), it does not include binding of the secondary insulin-specific, enzyme-linked antibody. To discount the possibility of non-specific protein-antibody interaction, we opted to include a titration step based on competitive antigen binding using non-labeled (cold) insulin. By increasing the amount of cold competitor in the binding solution we demonstrated concentration-dependent reduction in the radioactive signal bound to the plate (Fig. 6A). This also served the purpose of establishing the background radioactive signal resulting from non-specific protein-plate binding events. Initial experiments revealed two other challenges in successful implementation of the MRIA. Firstly, the background measurement was too high for sensitive applications (data not shown). This was most likely caused by non-specific binding of 'sticky' proteins, such as albumin, to the plate. Secondly, there was a large standard deviation across replicate sample measurements. Both these problems were overcome by incorporating an ultra-filtration step to remove proteins greater than $50 \mathrm{kDa}$ from the sample lysates and by pre-blocking the wells with non-labeled cell lysate.

To investigate the sensitivity of the MRIA (and further confirm the insulin specificity), a standard curve was generated by measuring the bound signal (cpm) detected in 
dilutions of labeled MIN6 lysate and plotting this against the concentration of insulin as measured by ELISA in this dilution series (Fig. 6B). Having established the utility of the assay in detecting insulin biosynthesis in MIN6 cells routinely down to levels below $5 \mathrm{ng} / \mathrm{ml}$, we were unable to detect de novo synthesis in lysate from S5 cells that contained $88 \mathrm{ng} / \mathrm{ml}$ insulin (as determined by standard commercial ELISA) (Fig. 7). Although it could be argued that the rate of insulin translation may be very low in these cells, it is unlikely to account for the high concentrations indicated by ELISA and the failure to detect any reduction in radioactive counts at high concentrations of competitor in the MRIA. This further supported the IF results that reveal a very small number of insulin-positive cells with a punctate, granular staining pattern indicative of a beta-cell type, i.e. storage of protein (and possibly lower turnover). The IF analysis also reveals a large amount of faint, more diffuse, non-granular insulin staining, not usually associated with a beta-cell phenotype. Taking these separate pieces of evidence together we propose that the diffuse staining seen in IF analyses is responsible for the high levels of insulin detected in S5 cell lysates by ELISA but is not cellderived, as it is not detected by MRIA. These findings are in agreement with previous reports suggesting insulin uptake from the culture medium to be responsible for the high insulin content in cells exposed to similar 5-stage differentiation protocols.

In conclusion, we have presented evidence to suggest that immunostaining methods for $\mathrm{C}$-peptide and insulin reactivity may not be definitive proof of - and may overestimate - betacell differentiation in ES-derived cultures and should be performed only in conjunction with other analysis methods. We also report on the development of a novel assay to enable the investigator to definitively detect the presence of labeled and, therefore, de novo synthesized, insulin above a certain threshold in cultured cells. These findings should assist in future studies aimed at generating renewable sources of betacells for diabetes therapy.

\section{Acknowledgment}

This work was supported by funding from the Ireland's Higher Educational Authority Program for Research in Third Level Institutes (PRTLI) Cycle 3.

\section{Appendix A. Supplementary data}

Supplementary data associated with this article can be found, in the online version, at doi:10.1016/j.yexcr.2006.12.013.

\section{REFERENCES}

[1] B. Soria, A. Skoudy, F. Martín, From stem cells to beta cells: new strategies in cell therapy of diabetes mellitus, Diabetologia 44 (2001) 407-415.

[2] G. Berná, T. León-Quinto, R. Enseñat-Waser, E. Montanya, F. Martín, B. Soria, Stem cells and diabetes, Biomed. Pharmacother. 55 (2001) 206-212.
[3] P. Blyszczuk, A.M. Wobus, Stem cells and pancreatic differentiation in vitro, J. Biotechnol. 113 (2004) 3-13.

[4] N. Lumelsky, O. Blondel, P. Laeng, I. Velasco, R. Ravin, R. McKay, Differentiation of embryonic stem cells to insulin-secreting structures similar to pancreatic islets, Science 292 (2001) 1389-1394.

[5] Y. Hori, I.C. Rulifson, B.C. Tsai, J.J. Heit, J.D. Cahoy, S.K. Kim, Growth inhibitors promote differentiation of insulin-producing tissue from embryonic stem cells, Proc. Natl. Acad. Sci. U. S. A. 99 (2002) 16105-16110.

[6] P. Blyszczuk, J. Czyz, G. Kania, M. Wagner, U. Roll, L. St-Onge, A.M. Wobus, Expression of pax 4 in embryonic stem cells promotes differentiation of nestin-positive progenitor and insulin-producing cells, Proc. Natl. Acad. Sci. U. S. A. 100 (2003) 998-1003.

[7] Y. Moritoh, E. Yamato, Y. Yasui, S. Miyazaki, J. Miyazaki, Analysis of insulin-producing cells during in vitro differentiation from feeder-free embryonic stem cells, Diabetes 52 (2003) 1163-1168.

[8] S. Miyazaki, E. Yamato, J. Miyazaki, Regulated expression of pdx1 promotes in vitro differentiation of insulin-producing cells from embryonic stem cells, Diabetes 53 (2004) 1030-1037.

[9] Y. Shi, L. Hou, F. Tang, W. Jiang, P. Wang, M. Ding, H. Deng, Inducing embryonic stem cells to differentiate into pancreatic $\beta$ cells by a novel three-step approach with activin A and all-trans retinoic acid, Stem Cells 23 (2005) 656-662.

[10] S. Assady, G. Maor, M. Amit, J. Itskovitz-Eldor, K.L. Skorecki, M. Tzukerman, Insulin production by human embryonic stem cells, Diabetes 50 (2001) 1691-1697.

[11] H. Segev, B. Fishman, A. Ziskind, M. Shulman, J. Itskovitz-Eldor, Differentiation of human embryonic stem cells into insulin-producing clusters, Stem Cells 22 (2004) 265-274.

[12] H. Li, S. Arber, T.M. Jessell, H. Edlund, Selective agenesis of the dorsal pancreas in mice lacking homeobox gene Hlxb9, Nat. Genet. 23 (1999) 67-70.

[13] V.M. Schwitzgebel, D.W. Scheel, J.R. Conners, J. Kalamaras, J.E. Lee, D.J. Anderson, L. Sussel, J.D. Johnson, M.S. German, Expression of neurogenin 3 reveals an islet cell precursor population in the pancreas, Development 127 (2000) 3533-3542.

[14] S.K. Kim, M. Hebrok, Intercellular signals regulating pancreas development and function, Genes Dev. 15 (2001) 111-127.

[15] H. Zulewski, E.J. Abraham, M. Gerlach, P.B. Daniel, W. Moritz, B. Müller, M. Vallejo, M.K. Thomas, J.F. Habener, Multipotential nestin-positive stem cells isolated from adult pancreatic islets differentiate ex vivo into pancreatic endocrine, exocrine, and hepatic phenotypes, Diabetes 50 (2001) 521-533.

[16] E.J. Abraham, C.A. Leech, J.C. Lin, H. Zulewski, J.F. Habener, Insulinotropic hormone glucagon-like peptide 1 differentiation of human pancreatic islet-derived progenitor cells into insulin-producing cells, Endocrinology 143 (2002) 3152-3161.

[17] J. Rajagopal, W.J. Anderson, S. Kume, O.I. Martinez, D.A. Melton, Insulin staining of ES cell progeny from insulin uptake, Science 299 (2003) 363.

[18] S. Sipione, A. Eshpeter, J.G. Lyon, G.S. Korbutt, R.C. Bleackley, Insulin expressing cells from embryonic stem cells are not beta cells, Diabetologia 47 (2004) 499-508.

[19] M. Hansson, A. Tonning, U. Frandsen, U. Frandsen, A. Petri, J. Rajagopal, M.C.O. Englund, R.S. Heller, J. Håkansson, J. Fleckner, H. Nilsson Sköld, D. Melton, H. Semb, P. Serup, Artifactual insulin release from differentiated embryonic stem cells, Diabetes 53 (2004) 2603-2609.

[20] H.M. Milne, C.J. Burns, I. Kitsou-Mylona, M.J. Luther, S.L. 
Minger, S.J. Persaud, P.M. Jones, Generation of

insulin-expressing cells from mouse embryonic stem cells, Biochem. Biophys. Res. Commun. 328 (2005) 399-403.

[21] L. O’Driscoll, P. Gammell, M. Clynes, Mechanisms associated with loss of glucose responsiveness in beta cells, Transplant. Proc. 36 (2004) 1159-1162.

[22] C. Wiese, A. Rolletschek, G. Kania, P. Blyszczuk, K.V. Tarasov,
R.P. Wersto, K.R. Boeheler, A.M. Wobus, Nestin expression-A property of multi-lineage progenitor cells? Cell. Mol. Life Sci. 61 (2004) 2510-2522.

[23] B.W. Kahan, L.M. Jacobson, D.A. Hullett, J.M. Ochoada, T.D. Oberley, K.M. Land, J.S. Odorico, Pancreatic precursors and differentiated islet cell types from murine embryonic stem cells, Diabetes 52 (2003) 2016-2024. 